\title{
Heat Capacities of Polyethylene from 2 to 360 K. II. Two High Density Linear Polyethylene Samples and Thermodynamic Properties of Crystalline Linear Polyethylene
}

\author{
S. S. Chang \\ Institute for Materials Research, National Bureau of Standards, Washington, D.C. 20234
}

(February 13, 1974)

\begin{abstract}
Heat capacities of two high density linear polyethylene samples were measured from 2 to $360 \mathrm{~K}$. By incorporating the results from the previous work of this series, thermodynamic properties of completely crystalline linear polyethylene may be estimated. $C_{p}, \mathrm{H}-\mathrm{H}_{0}, \mathrm{~S}$ and $-\left(\mathrm{G}-\mathrm{H}_{0}\right)$ at $298.15 \mathrm{~K}$ for crystalline linear polyethylene are estimated to be $22.60 \mathrm{~J} \mathrm{~K}^{-1} \mathrm{~mol}^{-1}, 3544 \mathrm{~J} \mathrm{~mol}^{-1}, 23.02 \mathrm{~J} \mathrm{~K}^{-1}$ $\mathrm{mol}^{-1}$ and $3319 \mathrm{~J} \mathrm{~mol}^{-1}$, respectively. Spontaneous adiabatic temperature drifts were observed in both samples near $240 \mathrm{~K}$. These drifts may be attributed to the enthalpy relaxation phenomena occurring in the glass transformation region.

Key words: Amorphous polyethylene; calorimetry; crystalline polyethylene; extended chain crvstals; glass transition temperature; heat capacity; linear polyethylene; polyethylene; thermodynamic properties.
\end{abstract}

\section{Introduction}

The heat capacity behaviors of two high density linear polyethylene samples were studied. These two samples were prepared from the same stock from which the standard reference material SRM 1475 for linear polyethylene whole polymer was established. By crystallizing slowly from the melt in vacuum, the degree of crystallinity of the sample was increased from the original value of 71 to 88 percent, as estimated from their densities. Another sample was crystallized under $5000 \mathrm{~atm}$ of pressure. The pressure-crystallized sample was composed mainly of extended-chain crystals and has a degree of crystallinity of 96 percent.

By combining the results from this work and from the previous work [1] ${ }^{1}$ on a sample of SRM 1475 in the condition as received, the thermodynamic properties of 100 percent crystalline linear polyethylene may be estimated.

Large spontaneous temperature drifts were observed in the temperature range centering around $235-240 \mathrm{~K}$ for both samples when quenched or annealed, as well as for the original sample of SRM 1475 after similar quenching and annealing procedures. These drifts, phenomenologically similar to that observed to occur in the glass transformation range of completely amorphous substances, are the basis of the assignment of the glass transition temperature in polyethylene.

\section{Experimental Detail}

\subsection{Calorimetry}

Heat capacity measurements on the two high density linear polyethylene samples were made with the same vacuum adiabatic calorimeter [2] as that used previously for the two samples of standard reference materials, SRM 1475 and SRM 1476 (linear and branched polyethylene whole polymers) in the conditions as received [1].

\subsection{Samples}

a. Slow Melt-Crystallized Linear Polyethylene

The density and the crystallinity of a sample of SRM 1475 linear polyethylene were increased by melting and recrystallizing the sample slowly in a mold in a vacuum oven. The sample was melted by heating to $170{ }^{\circ} \mathrm{C}$ and keeping it there for about $\mathrm{l} \mathrm{hr}$. It was then cooled to $150{ }^{\circ} \mathrm{C}$ in $1 \mathrm{hr}$. A rate of cooling of $0.75 \mathrm{~K} \mathrm{~h}^{-1}$ was maintained during the period when the sample was cooled from 150 to $90{ }^{\circ} \mathrm{C}$. The sample was then cooled to room temperature at a rate of a few degrees per hour.

The finished sample from the mold was in the shape of a cylinder, 5-cm O.D. and 6.3-cm long, with a hole of $1.3-\mathrm{cm}$ diam in the center. The density of the sample was $0.981 \mathrm{~g} \mathrm{~cm}^{-3}$ at $23{ }^{\circ} \mathrm{C}$ as determined in an ethanolwater density gradient column.

Small angle x-ray diffraction patterns were obtained from this sample. The long spacing of the sample 
was increased to $24.7 \mathrm{~nm}$ by the slow melt crystallization process. The new value is about twice the original value, $12.1 \mathrm{~nm}$. for the sample of SRM 1475 in the condition as received. The mass of the calorimetric sample was $93.105 \mathrm{~g}$ in vacuo. The density values of 0.981 and $0.00117 \mathrm{~g} \mathrm{~cm}^{-3}$ for the sample and for air, respectively, were used to estimate the buoyancy correction. No variation in the densities of the sample, before and after the calorimetric measurement, was detected beyond a range of $0.0005 \mathrm{~g} \mathrm{~cm}^{-3}$. Helium gas at a pressure of $12.5 \mathrm{~cm}$ of $\mathrm{Hg}$ was sealed in to facilitate the thermal conduction within the sample container.

\section{b. Pressure Crystallized Linear Polyethylene}

The crystallization of linear polyethylene sample under high pressure [3] was carried out as follows. A sample of SRM 1475 linear polyethylene was placed in a steel pressure vessel, $2.5-\mathrm{cm}$ I.D. and $2.5-\mathrm{cm}$ wall thickness, and then pumped down to a pressure of about $1 \times 10^{-4} \mathrm{~mm}$ of $\mathrm{Hg}$. After $2 \mathrm{~h}$, a sealing plug was forced into the bore and the vessel was disconnected from the vacuum line. A piston was used to push the plug in until the load reached $5000 \mathrm{lb}$. The whole vessel was then heated to $210^{\circ} \mathrm{C}$ while the position of the piston was kept constant. To do this the load on the piston was increased to about $60,000 \mathrm{lb}$ (equivalent to a pressure of $5150 \mathrm{~atm}$ ). The piston load was reduced in order to melt the polymer and then increased in $2500 \mathrm{lb}$ increments, followed by 5 -min waiting periods, to crystallize the sample under high pressure. Inward creep of the piston during the waiting period, indicative of crystallization, became significant at $48,000 \mathrm{lb}$ load but no apparently isobaric change in piston position occurred. The lack of such a change probably indicates that the pressure is not hydrostatic. At the same piston position, the load was $8000 \mathrm{lb}$ less when being withdrawn then being advanced. If the force at the polymer-sealing plug interface is the average of these, the pressure was 4800 atm when the load applied to the advancing piston was $60,000 \mathrm{lb}$. After $20 \mathrm{~min}$ the heaters were switched off and the load on the advancing piston was kept between 60,000 and $65,000 \mathrm{lb}$ as the vessel was cooled to $100{ }^{\circ} \mathrm{C}$. After cooling to $25^{\circ} \mathrm{C}$ over a $15 \mathrm{~h}$ period the load was 45,000 lb. The sealing plug was withdrawn and the sample removed.

In order to check the possibility that the increase in the density of the sample is not due to the oxidation of the polymer at elevated temperatures, the sample was subjected to infrared spectroscopic investigations. A film of $0.1 \mathrm{~mm}$ thick was prepared from the pressure-crystallized sample according to ASTM Method D-2238-64T. The IR spectrum of this film was examined in the region of $1700-1750 \mathrm{~cm}^{-1}$. The recorded trace indicated only a smooth base line within 0.002 in the absorbancy scale in that region. When the IR spectrum of a film of 0.5 percent CO-ethylene copolymer, $0.04 \mathrm{~mm}$ thick and similarly prepared, was examined under the same operational conditions, the absorption peaks in the region $1700-1750 \mathrm{~cm}^{-1}$ reached nearly full-scale of the recorder at about 1.23 in absorbancy scale. The peaks of a $0.05 \mathrm{~mm}$ film made from
1 percent CO-ethylene copolymer went off-scale in the same frequency region. Hence the oxygen content of the pressure-crystallized sample is probably much less than $10 \mathrm{ppm}$ and no significant oxidation has occurred during the high pressure and high temperature treatments in preparing the sample and the film.

The intrinsic viscosity of the pressure-crystallized sample in 1-chloronaphthalene at $130{ }^{\circ} \mathrm{C}$ is $0.915 \mathrm{dl} / \mathrm{g}$. The intrinsic viscosity of the SRM 1475 is $0.890 \mathrm{dl} / \mathrm{g}$ as reported in the certificate. Gel-permeation chromatograph, GPC, was also taken for the pressure-crystallized sample in order to detect any changes in the molecular weight distribution. The result of a single GPC run on the pressure-crystallized sample indicates an 8 percent increase in the $M_{n}$, a 3 percent increase in the $M_{w}$ and a 15 percent decrease in the $M_{z}$ over that of a calibration run of the SRM 1475. Except for the $M_{z}$, the changes are within the estimated standard deviations of the molecular weight determinations by GPC for SRM 1475 [4]. Apparently no drastic change of the polymer had occurred during the preparation of the sample under high pressure and high temperature.

The mass of the calorimetric sample was $63.836 \mathrm{~g}$ corrected to vacuum. The density values of 0.993 and $0.00117 \mathrm{~g} \mathrm{~cm}^{-3}$ for the sample and for air, respectively, were used to estimate the buoyancy correction. Helium gas at a pressure of $85 \mathrm{~mm}$ of $\mathrm{Hg}$ at room temperature was sealed in the sample container to facilitate the thermal conduction. The molar mass refers to the mass of the repeating unit $-\mathrm{CH}_{2}-, 14.027 \mathrm{~g}$.

\section{c. DSC Observations}

The melting behavior of the pressure-crystallized linear polyethylene sample was observed in a commercial dynamic differential scanning calorimeter (DSC). The extended-chain crystals of the pressurecrystallized sample melt at a higher temperature than the folded-chain crystals in either the as-received SRM 1475 or the slow melt-crystallized sample. However, just below the main melting peak, there is a small peak or shoulder which occurs at a temperature corresponding to the melting peak of the folded-chain crystals. The ratio of the energies involved for the first (lower temperatures) peak to the main peak varies varies between 2 to 10 percent from sample to sample, indicating some inhomogeneous distribution of small amount of folded-chain crystal in the pressure crystallized sample. Similar behavior in the pressurecrystallized linear polyethylene samples has also been observed by other investigators using differential thermal analysis [3,5] and DSC [6] techniques. Once the pressure-crystallized sample was melted and then recrystallized at atmospheric pressure, it behaved just like the ordinary linear polyethylene sample.

The energy required to melt the three linear polyethylene samples (as received, slow melt-crystallized, and pressure-crystallized) appears to be a linear function of the degree of crystallinity which is assumed to have a linear relationship with the specific volume of the sample. The heat of fusion for completely crystalline polyethylene is estimated at about 4100 $\mathrm{J} \mathrm{mol}^{-1}$ from the DSC experiment, if the value of 1.00 
$\mathrm{cm}^{3} \mathrm{~g}^{-1}$ is adopted as the specific volume for 100 percent crystalline polyethylene.

\section{Results}

\subsection{Representation of Data}

The results of the heat capacity measurement are tabulated in Table 1 and shown graphically in figure 1 . Also shown in figure 1 are the results from the previous work [1] for the linear polyethylene sample SRM 1475 in the condition as received and the branched polyethylene sample SRM 1476 in various conditions. Table 1 is arranged in the order of increasing initial temperature of a series of heat capacity determinations. The series are numbered in chronological sequence in order to facilitate the tracing of thermal history of the sample.

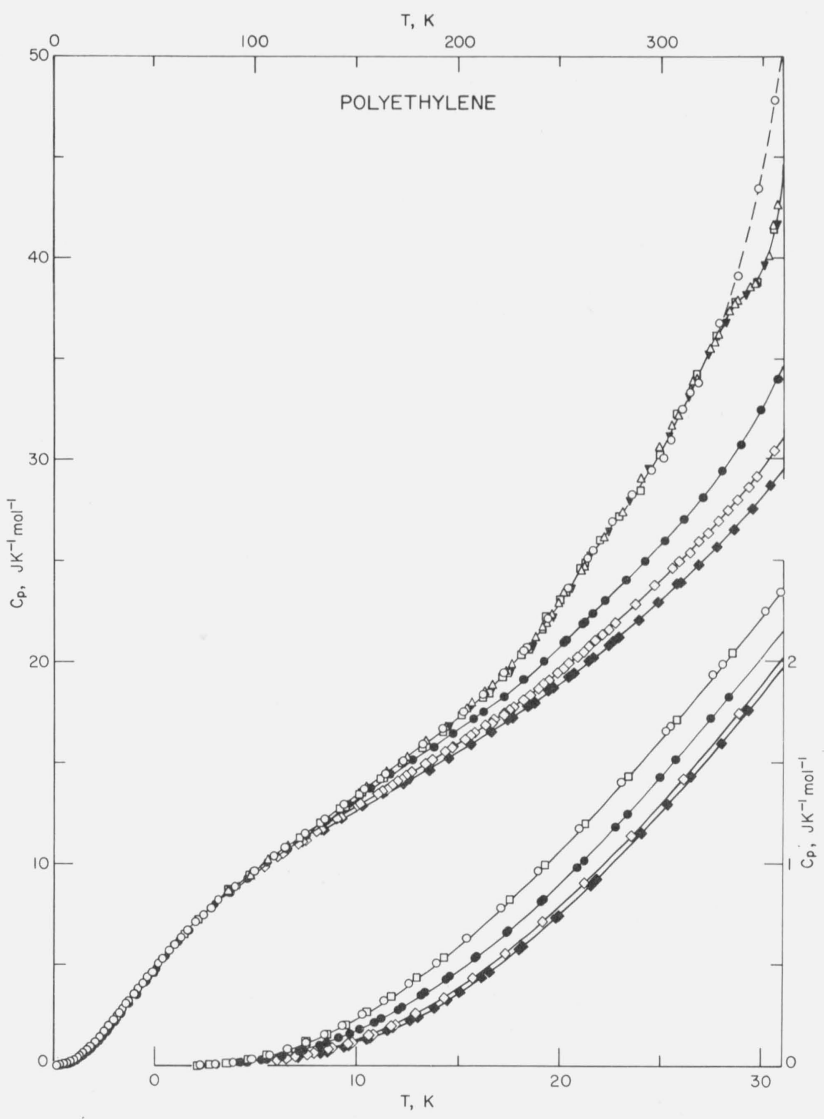

FIGURE 1. Heat capacities of polyethylene.

Linear, SRM 1475: as received [1], $>$ slow melt-crystallized, pressure-crystallized. Branched, SRM 1476 [1]: $\bigcirc$ as received, $\triangle$ stabilized at $360 \mathrm{~K}$ and then quenched, $\square$ annealed at $230 \mathrm{~K}, \boldsymbol{\nabla}$ slow-cooled.

Quenched samples are produced in the cryostat at a fast cooling rate of $4-5 \mathrm{~K} / \mathrm{min}$. Annealed samples are either produced by a slow cooling rate of $1-2$ $\mathrm{K} / \mathrm{h}$, or by holding at 220 to $225 \mathrm{~K}$ for one to three days followed by slow cooling. Series I of both samples represent measurements before any refrigerant being introduced into the cryostat. For the slow melt- crystallized sample, Series II-VI and XI represent heat capacity determinations after a quenching procedure, with the rest of the series represent that following an annealing procedure. For the pressured crystallized sample, Series II and VII-IX represent the measurement on the sample after quenching, while Series III and IV-VII represent that after slow cooling and annealing procedures.

The temperature increment for a heat capacity determination may be inferred from the differences in the mean temperatures of the adjacent determination within the series. Curvature corrections have been added to correct for the effect of the finite temperature rise of a determination. The precision of the measurement above $25 \mathrm{~K}$ is in the order of 0.05 percent. Below $25 \mathrm{~K}$, the precision graduately changes to 1 percent at $5 \mathrm{~K}$ and about 5 percent at $2 \mathrm{~K}$. The accuracy over most of the temperature range of the measurement is believed to be comparable to the precision as seen from the result of the heat capacity measurement on a Calorimetry Conference standard sample of sapphire [2].

Smoothed heat capacity values at rounded temperatures along with values of other derived thermodynamic functions are listed in table $2 . \mathrm{H}_{0}$ and $\mathrm{S}_{0}$ refers to the zero point enthalpy and the residual entropy of the individual samples. Since these samples are expected to have undetermined residual entropies at $0 \mathrm{~K}$. Gibbs free energies for these samples are not given in table 2 .

\subsection{Estimation of $C_{p}$ of Crystalline Linear Polyethylene}

Heat capacities of linear and branched polyethylene samples from several literature sources as well as those from this research are plotted at selected temperatures as a function of specific volume at room temperature in figure 2. Literature values [7-12] included in figure 2 are those where the densities of the samples are given. The degrees of crystallinity of the samples are interpolated linearly between the specific volume of $1.00 \mathrm{~cm}^{3} \mathrm{~g}^{-1}$ for the crystalline part and $1.17 \mathrm{~cm}^{-3} \mathrm{~g}^{-1}$ for the amorphous part.

In order to minimize the effects due to the differences in chemical compositions and due to the differences in the laboratory techniques, the heat capacity of 100 percent crystalline linear polyethylene was estimated only from the results obtained in this laboratory for the three linear polyethylene samples which are derived from the same stock as that used to establish the SRM-1475. The heat capacities of these three samples ranging from 71 to 96 percent crystallinity are represented by the filled circles. The temperatures are denoted by the numbers nearby the straight lines. The straight lines are obtained by a least-squares fitting procedure through the data for the three samples. From 30 to $360 \mathrm{~K}$, the maximum deviations of the data points from the generated lines are less than 0.4 percent. Apparently the two-phase additive model is applicable at high crystalline contents. Since the extrapolated range of crystallinity is only 4 percent, it is believed that the heat capacity of 100 percent crystalline linear polyethylene may be estimated to 
TABLE 1. Heat capacity of linear polyethylene

(base mole $\left[-\mathrm{CH}_{2}-\right]=14.027$ )

Slow melt-crystallized SRM $1475\left(\rho_{23}{ }^{\circ} \mathrm{c}=0.981 \mathrm{~g} \mathrm{~cm}^{-3}\right)$

\begin{tabular}{|c|c|c|c|c|c|}
\hline$T$ & $C_{p}, \mathrm{~J} \mathrm{~K}^{-1} \mathrm{~mol}^{-1}$ & $T$ & $C_{p}, \mathrm{~J} \mathrm{~K}^{-1} \mathrm{~mol}^{-1}$ & $T$ & $C_{p}, \mathrm{~J} \mathrm{~K}^{-1} \mathrm{~mol}^{-1}$ \\
\hline 8 & SERIES VIII & \multirow[b]{2}{*}{38.49} & SERIES VII & \multirow[b]{2}{*}{196.07} & SERIES XI \\
\hline 2.29 & 0.0014 & & 2.998 & & 15.78 \\
\hline 2.96 & .0034 & 42.13 & 3.485 & 204.96 & 16.36 \\
\hline 3.72 & .0070 & 46.12 & 4.016 & 212.83 & 16.88 \\
\hline 4.55 & .0132 & 50.62 & 4.607 & 221.64 & 17.48 \\
\hline 5.49 & .0234 & \multirow[t]{2}{*}{55.96} & 5.282 & 231.38 & 18.15 \\
\hline 6.51 & .0385 & & SERIES XII & 241.13 & 18.87 \\
\hline 7.56 & .0593 & 84.99 & 8.319 & 250.98 & 19.64 \\
\hline 8.56 & .0844 & 94.24 & 9.091 & 260.81 & 20.48 \\
\hline 9.52 & .115 & 104.10 & 9.839 & 270.52 & 21.33 \\
\hline 10.51 & .151 & \multirow{2}{*}{$\begin{array}{l}113.77 \\
123.47\end{array}$} & & \multirow{3}{*}{$\begin{array}{l}205.49 \\
215.02\end{array}$} & SERIES X \\
\hline 11.60 & .198 & & 11.156 & & \multirow{2}{*}{$\begin{array}{l}16.33 \\
16.96\end{array}$} \\
\hline \multirow[t]{2}{*}{12.82} & .260 & \multirow{3}{*}{$\begin{array}{l}86.10 \\
94.53\end{array}$} & SERIES II & & \\
\hline & SERIES IX & & 8.347 & 224.57 & 17.61 \\
\hline \multirow{2}{*}{$\begin{array}{l}6.03 \\
6.91\end{array}$} & .0304 & & 9.117 & \multirow{3}{*}{$\begin{array}{l}234.13 \\
243.78 \\
253.50\end{array}$} & 18.32 \\
\hline & \multirow{2}{*}{$\begin{array}{l}.0457 \\
.0654\end{array}$} & \multirow[t]{2}{*}{104.02} & 9.837 & & 19.10 \\
\hline 7.82 & & & SERIES III & & 19.89 \\
\hline 8.75 & .0901 & 110.67 & 10.31 & 263.30 & 20.73 \\
\hline 9.67 & .120 & 120.20 & 10.95 & 273.08 & 21.58 \\
\hline 10.62 & .156 & 129.91 & 11.58 & & SERIES XIV \\
\hline 11.68 & .202 & 139.85 & 12.22 & 221.53 & 17.40 \\
\hline 12.88 & .263 & 149.80 & 12.85 & 231.27 & 18.11 \\
\hline 14.21 & .339 & 159.70 & 13.48 & 241.00 & 18.87 \\
\hline 15.61 & .434 & 169.57 & 14.10 & 250.71 & 19.65 \\
\hline 17.21 & .553 & & SERIES XIII & 260.41 & 20.47 \\
\hline 19.09 & .711 & 122.61 & 11.11 & 270.19 & 21.33 \\
\hline 21.17 & .903 & 131.47 & 11.69 & & SERIES V \\
\hline 23.47 & 1.138 & 141.44 & 12.31 & 238.47 & 18.68 \\
\hline 26.02 & 1.421 & 151.55 & 12.96 & 248.09 & 19.44 \\
\hline 28.81 & 1.748 & 161.60 & 13.59 & 258.08 & 20.25 \\
\hline 31.90 & 2.133 & 171.51 & 14.20 & & SERIES VI \\
\hline 35.32 & 2.579 & & SERIES XV & 266.89 & 21.03 \\
\hline 39.10 & 3.081 & 164.06 & 13.66 & 276.47 & 21.93 \\
\hline 45.55 & 3.940 & 173.61 & 14.32 & 286.14 & 22.82 \\
\hline 52.17 & 4.806 & 183.16 & 14.92 & 295.87 & 23.75 \\
\hline 57.23 & 5.438 & 192.82 & 15.52 & 305.58 & 24.67 \\
\hline 63.02 & 6.118 & 202.70 & 16.15 & & SERIES I \\
\hline 69.24 & 6.799 & & SERIES IV & 304.88 & 24.59 \\
\hline 76.40 & 7.523 & 166.34 & 13.89 & 313.62 & 25.47 \\
\hline 84.18 & 8.246 & 176.19 & 14.52 & 322.76 & 26.39 \\
\hline & & 186.23 & 15.15 & 332.43 & 27.42 \\
\hline & & 196.47 & 15.81 & 342.43 & 28.66 \\
\hline & & 206.71 & 16.48 & & SERIES XVI \\
\hline & & 216.75 & 17.14 & 308.36 & 24.92 \\
\hline & & 226.53 & 17.81 & 318.13 & 25.92 \\
\hline & & & & 327.79 & 26.91 \\
\hline & & & & 337.17 & 27.98 \\
\hline & & & & 346.27 & 29.13 \\
\hline & & & & 355.08 & 30.43 \\
\hline
\end{tabular}




\begin{tabular}{|c|c|c|c|c|c|}
\hline \multicolumn{6}{|c|}{ Pressure-crystallized SRM $1475\left(\rho_{23}{ }^{\circ} \mathrm{C}=0.993 \mathrm{~g} \mathrm{~cm}^{-3}\right)$} \\
\hline$T$ & $C_{p}, \mathrm{~J} \mathrm{~K}^{-1} \mathrm{~mol}^{-1}$ & $T$ & $C_{p}, \mathrm{~J} \mathrm{~K}^{-1} \mathrm{~mol}^{-1}$ & $T$ & $C_{p}, \mathrm{~J} \mathrm{~K}^{-1} \mathrm{~mol}^{-1}$ \\
\hline \multirow[b]{2}{*}{2.74} & SERIES VIII & \multirow[b]{2}{*}{2.32} & SERIES IV & \multirow[b]{2}{*}{175.30} & SERIES III \\
\hline & .0034 & & 0.0019 & & 14.13 \\
\hline 3.62 & .0061 & 3.00 & .0038 & 184.83 & 14.69 \\
\hline 4.61 & .0126 & 3.92 & .0080 & 194.77 & 15.28 \\
\hline 5.54 & .0210 & 4.97 & .0152 & 205.11 & 15.91 \\
\hline 6.51 & .0335 & 6.01 & .0262 & 215.51 & 16.56 \\
\hline 7.51 & .0513 & 7.00 & .0413 & 225.65 & 17.24 \\
\hline 8.55 & .0744 & 8.14 & .0636 & \multirow[b]{2}{*}{203.73} & SERIES II \\
\hline 9.58 & .1040 & 9.33 & .0956 & & 15.86 \\
\hline 10.63 & .1399 & 10.41 & .1310 & 213.51 & 16.47 \\
\hline 11.74 & .1855 & 11.47 & .1718 & 223.48 & 17.11 \\
\hline 12.96 & .2456 & 12.55 & .2250 & 233.53 & 17.80 \\
\hline 14.38 & .3243 & 13.70 & .2841 & 243.53 & 18.52 \\
\hline 16.06 & .4364 & 15.00 & .3625 & 253.49 & 19.25 \\
\hline 17.90 & .5761 & 16.45 & .4638 & 263.41 & 20.04 \\
\hline \multirow{2}{*}{$\begin{array}{l}19.77 \\
21.75\end{array}$} & .7375 & 18.08 & .5903 & \multirow[t]{2}{*}{273.28} & 20.82 \\
\hline & .9240 & 19.85 & .7424 & & SERIES VII \\
\hline 23.95 & 1.152 & 21.45 & .8933 & 206.68 & 16.02 \\
\hline 26.46 & 1.433 & 23.11 & 1.061 & 216.39 & 16.63 \\
\hline 29.26 & 1.763 & 25.24 & 1.292 & 226.32 & 17.28 \\
\hline 32.27 & 2.144 & 27.94 & 1.604 & 236.31 & 17.98 \\
\hline 35.46 & 2.562 & 31.06 & 1.987 & 246.22 & 18.73 \\
\hline 38.98 & 3.032 & 34.28 & 2.414 & 255.99 & 19.46 \\
\hline 43.04 & 3.576 & 37.84 & 2.873 & 265.62 & 20.23 \\
\hline \multirow{20}{*}{$\begin{array}{l}47.54 \\
52.42\end{array}$} & 4.178 & 41.92 & 3.425 & 275.31 & 21.03 \\
\hline & 4.818 & 46.44 & 4.030 & \multirow{6}{*}{$\begin{array}{l}278.29 \\
287.99 \\
297.74 \\
307.63\end{array}$} & SERIES IX \\
\hline & & 51.32 & 4.674 & & 21.22 \\
\hline & & 56.71 & 5.356 & & 22.08 \\
\hline & & & SERIES V & & 22.96 \\
\hline & & 60.51 & 5.814 & & 23.85 \\
\hline & & $66.5 \dot{5}$ & 6.497 & & SERIES I \\
\hline & & 73.07 & 7.185 & \multirow{13}{*}{$\begin{array}{l}309.03 \\
318.10 \\
326.96 \\
335.80 \\
344.60 \\
353.35\end{array}$} & 23.90 \\
\hline & & 80.32 & 7.887 & & 24.79 \\
\hline & & 88.58 & 8.619 & & 25.64 \\
\hline & & 97.74 & 9.352 & & 26.58 \\
\hline & & 107.60 & 10.07 & & 27.59 \\
\hline & & 117.99 & 10.77 & & 28.71 \\
\hline & & 128.28 & 11.41 & & \\
\hline & & & SERIES VI & & \\
\hline & & 133.00 & 11.70 & & \\
\hline & & 142.79 & 12.28 & & \\
\hline & & 152.70 & 12.86 & & \\
\hline & & 162.63 & 13.43 & & \\
\hline & & 172.50 & 13.99 & & \\
\hline
\end{tabular}

within 1-2 percent over the majority of the temperature range investigated.

The extrapolated heat capacity values for 100 percent crystalline polyethylene are listed in table 3 along with calculated thermodynamic functions. Also listed in table 3 are linearly extrapolated heat capacity values for amorphous linear polyethylene. The reliability of such an extrapolation for the amorphous phase, especially at temperatures above $250 \mathrm{~K}$, is less certain than that for its crystalline counterpart, not only because the range of extrapolation is much longer than that of the measurement, but also due to the uncertainty in applying the simple two phase additive model over a long extrapolation region. The heat capacity curves for the three linear samples, figure 1, show curvatures concaved upward at temperatures above $300 \mathrm{~K}$. These features are probably caused by premelt- ing or melting of small crystallites. Gibbs free energy functions for the amorphous phase are not included in table 3 because of the existence of an undetermined residual entropy.

The extrapolated heat capacity for crystalline linear polyethylene is a relatively smooth function of temperature. The smoothness may be visualized in the $C_{p} / T, d C_{p} / d T$ and $d \ln C_{p} / d T$ versus $T$ plots, as shown in figure 3. Similar functions for SRM 1475 and SRM 1476 in the condition as received [1] are also shown in figure 3 for comparison. The slight irregularities observed around $290 \mathrm{~K}$ in the extrapolated crystalline heat capacity are probably the result of some experimental uncertainties. However, pronounced features centering around 150 and $250 \mathrm{~K}$ show up in the behavior of the linear and branched polyethylene samples. 
TABLE 2. Thermodynamic functions of polyethylene (units in J, $\mathrm{K}$ and $\mathrm{mol}$; base mole $\left[-\mathrm{CH}_{2}-\right]=14.027$ )

\begin{tabular}{|c|c|c|c|c|c|c|}
\hline \multicolumn{4}{|c|}{ Slow melt-crystalilized SRM 1475} & \multicolumn{3}{|c|}{ Pressure-crystallized SRM $1475^{\circ}$} \\
\hline$T$ & $C_{p}$ & $\mathrm{H}-\mathrm{H}_{0}^{s}$ & $\mathrm{~S}-\mathrm{S}_{0}^{s}$ & $C_{p}$ & $\mathrm{H}-\mathrm{H}_{0}^{p}$ & $\mathrm{~S}-\mathrm{S}_{0}^{p}$ \\
\hline 5 & 0.018 & 0.021 & 0.006 & 0.015 & 0.020 & 0.005 \\
\hline 10 & .131 & .339 & .045 & .117 & .298 & .040 \\
\hline 15 & .391 & 1.583 & .143 & .363 & 1.434 & .129 \\
\hline 20 & .793 & 4.490 & .307 & .757 & 4.177 & .284 \\
\hline 25 & 1.305 & 9.696 & .537 & 1.265 & 9.191 & .506 \\
\hline 30 & 1.895 & 17.67 & .826 & 1.854 & 16.96 & .787 \\
\hline 35 & 2.536 & 28.73 & 1.166 & 2.499 & 27.83 & 1.121 \\
\hline 40 & 3.202 & 43.07 & 1.548 & 3.168 & 41.99 & 1.498 \\
\hline 45 & 3.870 & 60.75 & 1.964 & 3.841 & 59.52 & 1.910 \\
\hline 50 & 4.526 & 81.75 & 2.406 & 4.502 & 80.38 & 2.349 \\
\hline 60 & 5.766 & 133.3 & 3.342 & 5.750 & 131.7 & 3.282 \\
\hline 70 & 6.882 & 196.7 & 4.317 & 6.870 & 195.0 & 4.255 \\
\hline 80 & 7.871 & 270.5 & 5.301 & 7.860 & 268.7 & 5.238 \\
\hline 90 & 8.747 & 353.7 & 6.280 & 8.736 & 351.8 & 6.215 \\
\hline 100 & 9.535 & 445.2 & 7.243 & 9.522 & 443.1 & 7.177 \\
\hline 110 & 10.26 & 544.2 & 8.186 & 10.24 & 542.0 & 8.119 \\
\hline 120 & 10.94 & 650.2 & 9.108 & 10.90 & 647.7 & 9.038 \\
\hline 130 & 11.59 & 762.8 & 10.01 & 11.52 & 759.8 & 9.935 \\
\hline 140 & 12.22 & 881. & 10.89 & 12.11 & 878.0 & 10.81 \\
\hline 150 & 12.86 & 1007. & 11.76 & 12.70 & 1002. & 11.67 \\
\hline 160 & 13.49 & 1139. & 12.61 & 13.27 & 1132. & 12.50 \\
\hline 170 & 14.12 & 1277. & 13.44 & 13.84 & 1267. & 13.33 \\
\hline 180 & 14.74 & 1421. & 14.27 & 14.42 & 1409. & 14.13 \\
\hline 190 & 15.37 & 1572. & 15.08 & 15.00 & 1556. & 14.93 \\
\hline 200 & 16.01 & 1729. & 15.89 & 15.60 & 1709. & 15.71 \\
\hline 210 & 16.66 & 1892. & 16.68 & 16.22 & 1868. & 16.49 \\
\hline 220 & 17.33 & 2062 . & 17.47 & 16.86 & 2033. & 17.26 \\
\hline 230 & 18.04 & 2239 . & 18.26 & 17.54 & 2205 . & 18.02 \\
\hline 240 & 18.79 & 2423. & 19.04 & 18.26 & 2384 . & 18.78 \\
\hline 250 & 19.59 & 2615 . & 19.83 & 19.00 & 2571 . & 19.55 \\
\hline 260 & 20.42 & 2815 . & 20.61 & 19.76 & 2765 . & 20.31 \\
\hline 270 & 21.31 & 3023. & 21.40 & 20.56 & 2966. & 21.07 \\
\hline 280 & 22.24 & 3241 . & 22.19 & 21.39 & 3176. & 21.83 \\
\hline 290 & 23.18 & 3468. & 22.99 & 22.26 & 3394. & 22.59 \\
\hline 300 & 24.14 & 3705 . & 23.79 & 23.14 & 3621. & 23.36 \\
\hline 310 & 25.10 & 3951. & 24.60 & 24.05 & 3857. & 24.14 \\
\hline 320 & 26.10 & 4207. & 25.41 & 24.99 & 4102 & 24.92 \\
\hline 330 & 27.16 & 4473 . & 26.23 & 25.97 & 4357. & 25.70 \\
\hline 340 & 28.33 & 4750 . & 27.06 & 27.04 & 4621. & 26.49 \\
\hline 350 & 29.67 & 5040 . & 27.90 & 28.26 & 4898. & 27.29 \\
\hline 360 & 31.23 & 5345. & 28.75 & 29.72 & 5188. & 28.11 \\
\hline 273.15 & 21.60 & 3091. & 21.65 & 20.82 & 3031. & 21.31 \\
\hline 298.15 & 23.96 & 3660 . & 23.64 & 22.98 & 3578. & 23.22 \\
\hline
\end{tabular}

The superscripts of $s$ and $p$ for the zero-point enthalpy and entropy values denote the reference states of slow melt-crystallized and pressure-crystallized polyethylene, respectively. 

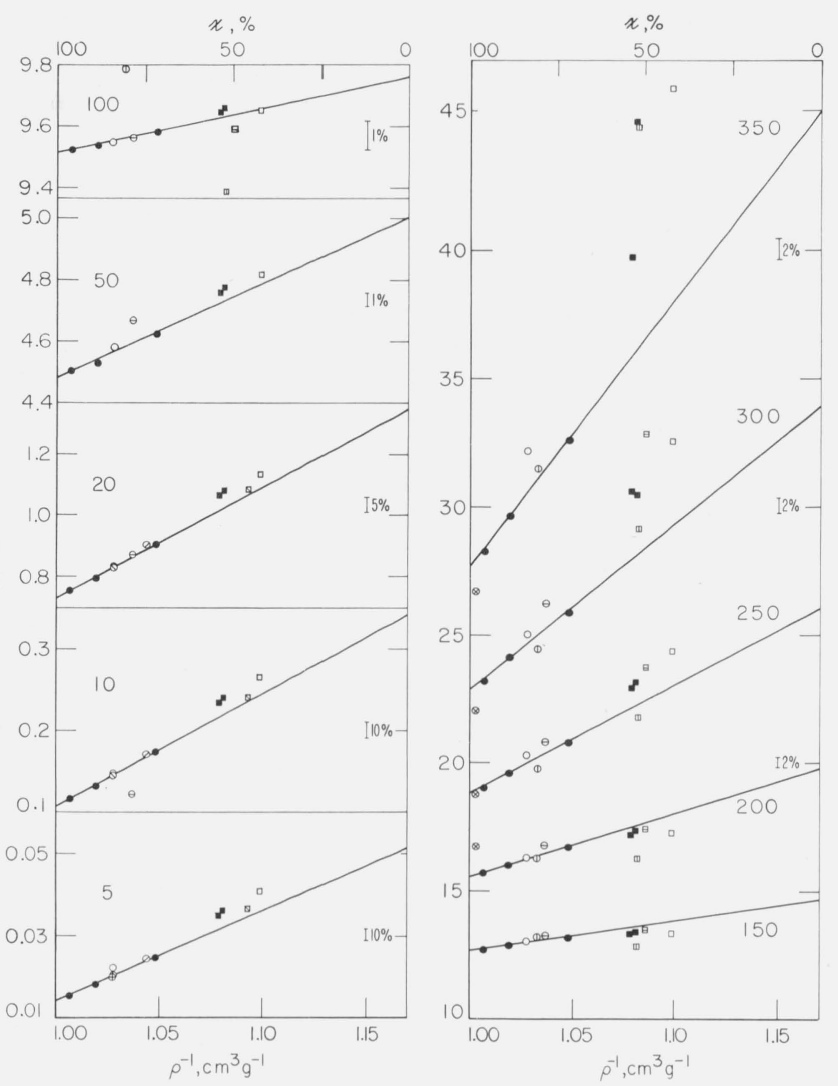

FIGURE 2. Heat capacity of polyethylene as a function of specific volume.

Circles-linear polyethylene. Squres-Branched polyethylene. This work and previous work [I], $\ominus$ 日ainton et al. [7], $\bigcirc$ Isaacs et al. [8], $\bigcirc \square$ Passaglia et al. [9], $\varnothing \varnothing \triangle$ Tucker et al. [10], $\bigcirc$ Westrum [11], $\otimes$ Wunderlich [12].

The extrapolated values of crystalline and amorphous linear polyethylene from this investigation are plotted in figure 4 along with estimated values of crystalline, amorphous and liquid polyethylene from other sources. The $C_{p}$ of ideal $\mathrm{CH}_{2}$ chain crystal estimated by Broadhurst [13] from the $n$-paraffin data is in general higher than those obtained from this investigation, although the experimental $n$-paraffin values up to $200 \mathrm{~K}$ are slightly lower. Between 2 and $30 \mathrm{~K}$, Tucker and Reese's values for the crystalline phase based on their measurements, are very close to ours, and is therefore not shown in figure 4. However, their estimated values from 30 to $150 \mathrm{~K}$, with identical heat capacity for the crystalline and the amorphous phases from 60 to $150 \mathrm{~K}$, lie inbetween our values for the two phases, but closer to our values for the crystalline phase. In an earlier estimate by Wunderlich [14] the values for the crystalline phase is identical to that of the amorphous phase for temperatures below $110 \mathrm{~K}$. These values are somewhat higher than the estimated crystalline heat capacity from this research. At higher temperatures the values for the crystalline heat capacity are also higher than that from this research. The more recent estimate by Wunderlich [15] is based upon Tucker and Reese's estimate up to $150 \mathrm{~K}$ and is then made to join at 210 $\mathrm{K}$ the results of a differential scanning calorimetric work on extended chain crystals from $180 \mathrm{~K}$ [12]. The results of the DSC work are lower than the values for crystalline phase from this research at temperatures above $250 \mathrm{~K}$. In both Wunderlich's estimates, there is a pronounced dip in heat capacity around $250 \mathrm{~K}$. However Wunderlich's calculated values [12] based on a spectrum assigned earlier [16] agree relatively well with the result from this research over a wide temperature range.

For the amorphous phase, the estimation of Tucker and Reese [10] below $30 \mathrm{~K}$ agrees relatively well with our estimation for the amorphous phase. Because of the closeness of the two estimations, their values are not shown in figure 4 . However their estimation to $150 \mathrm{~K}$ and the conclusion that the amorphous and the crystalline phases have identical heat capacity do not agree with the findings from this investigation. Two estimates of heat capacity of amorphous polyethylene have been made by Wunderlich. The earlier one [14] assumes identical heat capacity behavior for the amorphous and crystalline phases for temperatures below $110 \mathrm{~K}$. The more recent one [15] incorporates the estimate by Tucker and Reese for temperatures below $150 \mathrm{~K}$ and assumes identical heat capacity values for the two phases between 60 and $210 \mathrm{~K}$. Both Wunderlich's estimates for the amorphous phase are terminated around $250 \mathrm{~K}$ by the linear extrapolation of the liquid heat capacity above the melting point.

Heat capacity of the liquid and the supercooled liquid polyethylene from $200 \mathrm{~K}$ up has been estimated by many authors. Broadhurst [13] has estimated the $C_{p}$ of ideal $\mathrm{CH}_{2}$ chain liquid from $n$-paraffin data from 200 to $370 \mathrm{~K}$. Atkinson, Larkin, and Richardson [17] have based their estimates on their measurement of liquid polyethylene above the melting point and $n$-paraffin data at lower temperatures. Wunderlich's earlier estimates [14] of liquid polyethylene $C_{p}$ are the linear extrapolations from the liquid heat capacity of a sample of Marlex ${ }^{2} 50$ above the melting point in reference [18]. The more recent estimates [15] of Wunderlich were extrapolated from the average values of a collection of liquid polyethylene data.

\subsection{Comparison of Results of Different Polyethylene Samples}

Low temperature heat capacity behavior of various polyethylene samples are plotted in figure 5 . As mentioned earlier [1], the heat capacities of the linear SRM 1475 sample and the branched SRM 1476 sample in conditions as received agree within 1-2 percent of the values reported for M2 and low density samples, respectively, studied by Tucker and Reese [10]. The reason for the closeness in agreement

${ }^{2} \mathrm{~A}$ commercial material is identified in this paper in order to adequately specify the experimental procedure. Such identification does not imply recommendation or endorsement by the National Bureau of Standards. 
TABLE 3. Thermodynamic properties of extrapolated crystalline and amorphous polyethylene (units in $\mathrm{J}, \mathrm{K}$, and $\mathrm{mol} ;-\mathrm{CH}_{2}-=14.027$ )

\begin{tabular}{|c|c|c|c|c|c|c|c|}
\hline \multicolumn{5}{|c|}{ Crystalline } & \multicolumn{3}{|c|}{ Amorphous } \\
\hline$T$ & $C_{p}$ & $\mathrm{H}-\mathrm{H}_{\delta}$ & $S$ & $-\left(\mathrm{G}-\mathrm{H}_{0}^{c}\right)$ & $C_{p}$ & $\mathrm{H}-\mathrm{H}_{0}^{a}$ & $\mathbf{S}-\mathbf{S}_{0}^{q}$ \\
\hline 5 & 0.014 & 0.018 & 0.005 & 0.006 & 0.051 & 0.057 & 0.014 \\
\hline 10 & .106 & .267 & .036 & .092 & .341 & .943 & .126 \\
\hline 15 & .342 & 1.323 & .118 & .451 & .800 & 3.747 & .347 \\
\hline 20 & .727 & 3.939 & .266 & 1.384 & 1.346 & 9.088 & .650 \\
\hline 25 & 1.231 & 8.794 & .481 & 3.225 & 1.937 & 17.28 & 1.014 \\
\hline 30 & 1.819 & 16.39 & .756 & 6.293 & 2.547 & 28.49 & 1.421 \\
\hline 35 & 2.465 & 27.08 & 1.084 & 10.87 & 3.167 & 42.76 & 1.860 \\
\hline 40 & 3.135 & 41.07 & 1.457 & 17.21 & 3.788 & 60.15 & 2.323 \\
\hline 45 & 3.811 & 58.44 & 1.865 & 25.51 & 4.398 & 80.62 & 2.805 \\
\hline 50 & 4.475 & 79.16 & 2.302 & 35.91 & 4.991 & 104.1 & 3.299 \\
\hline 60 & 5.730 & 130.3 & 3.230 & 63.52 & 6.115 & 159.7 & 4.309 \\
\hline 70 & 6.855 & 193.3 & 4.200 & 100.7 & 7.144 & 226.1 & 5.330 \\
\hline 80 & 7.847 & 266.9 & 5.181 & 147.6 & 8.079 & 302.3 & 6.346 \\
\hline 90 & 8.725 & 349.9 & 6.157 & 204.3 & 8.934 & 387.4 & 7.348 \\
\hline 100 & 9.511 & 441.1 & 7.118 & 270.6 & 9.737 & 480.8 & 8.331 \\
\hline 110 & 10.23 & 539.9 & 8.058 & 346.5 & 10.53 & 582.1 & 9.296 \\
\hline 120 & 10.88 & 645.4 & 8.976 & 431.7 & 11.35 & 691.4 & 10.25 \\
\hline 130 & 11.49 & 757.3 & 9.872 & 526.0 & 12.27 & 809.4 & 11.19 \\
\hline 140 & 12.07 & 875.1 & 10.75 & 629.1 & 13.38 & 937.4 & 12.14 \\
\hline 150 & 12.62 & 998.6 & 11.60 & 740.8 & 14.60 & 1077. & 13.10 \\
\hline 160 & 13.17 & 1128. & 12.43 & 861.0 & 15.78 & 1229. & 14.08 \\
\hline 170 & 13.73 & 1262. & 13.24 & 989.3 & 16.88 & 1393. & 15.07 \\
\hline 180 & 14.30 & 1402. & 14.04 & 1126. & 17.89 & 1567. & 16.07 \\
\hline 190 & 14.87 & 1548. & 14.83 & 1270. & 18.81 & 1750. & 17.06 \\
\hline 200 & 15.47 & 1700. & 15.61 & 1422. & 19.72 & 1943. & 18.05 \\
\hline 210 & 16.08 & 1857. & 16.38 & 1582. & 20.66 & 2145. & 19.03 \\
\hline 220 & 16.70 & 2021. & 17.14 & 1750. & 21.70 & 2356. & 20.02 \\
\hline 230 & 17.35 & 2192. & 17.90 & 1925. & 22.91 & 2579. & 21.01 \\
\hline 240 & 18.03 & 2368. & 18.65 & 2108. & 24.32 & 2815. & 22.01 \\
\hline 250 & 18.72 & 2552. & 19.40 & 2298. & 25.95 & 3066. & 23.04 \\
\hline 260 & 19.45 & 2743. & 20.15 & 2496. & 27.64 & 3334. & 24.09 \\
\hline 270 & 20.23 & 2941. & 20.90 & 2701. & 29.29 & 3619. & 25.16 \\
\hline 280 & 21.04 & 3148. & 21.65 & 2914. & 30.86 & 3920. & 26.26 \\
\hline 290 & 21.89 & 3362. & 22.40 & 3134. & 32.36 & 4236. & 27.37 \\
\hline 300 & 22.76 & 3586. & 23.16 & 3362. & 33.85 & 4567. & 28.49 \\
\hline 310 & 23.64 & 3618. & 23.92 & 3597. & 35.45 & 4913. & 29.62 \\
\hline 320 & 24.54 & 4058. & 24.68 & 3841. & 37.26 & 5277. & 30.78 \\
\hline 330 & 25.46 & 4308. & 25.45 & 4091. & 39.43 & 5660. & 31.95 \\
\hline 340 & 26.46 & 4568. & 26.23 & 4350. & 42.09 & 6067. & 33.17 \\
\hline 350 & 27.57 & 4838. & 27.01 & 4616. & 45.33 & 6503. & 34.44 \\
\hline 360 & 28.90 & 5120. & 27.81 & 4890. & 49.21 & 6975. & 35.76 \\
\hline 273.15 & 20.48 & 3006. & 21.14 & 2768. & 29.79 & 3712. & 25.51 \\
\hline 298.15 & 22.60 & 3544 . & 23.02 & 3319. & 33.57 & 4504 . & 28.28 \\
\hline
\end{tabular}

The superscripts of $a$ and $c$ for the zero-point enthalpy and entropy values denote the reference states of amorphous and crystalline polyethylene respectively. 


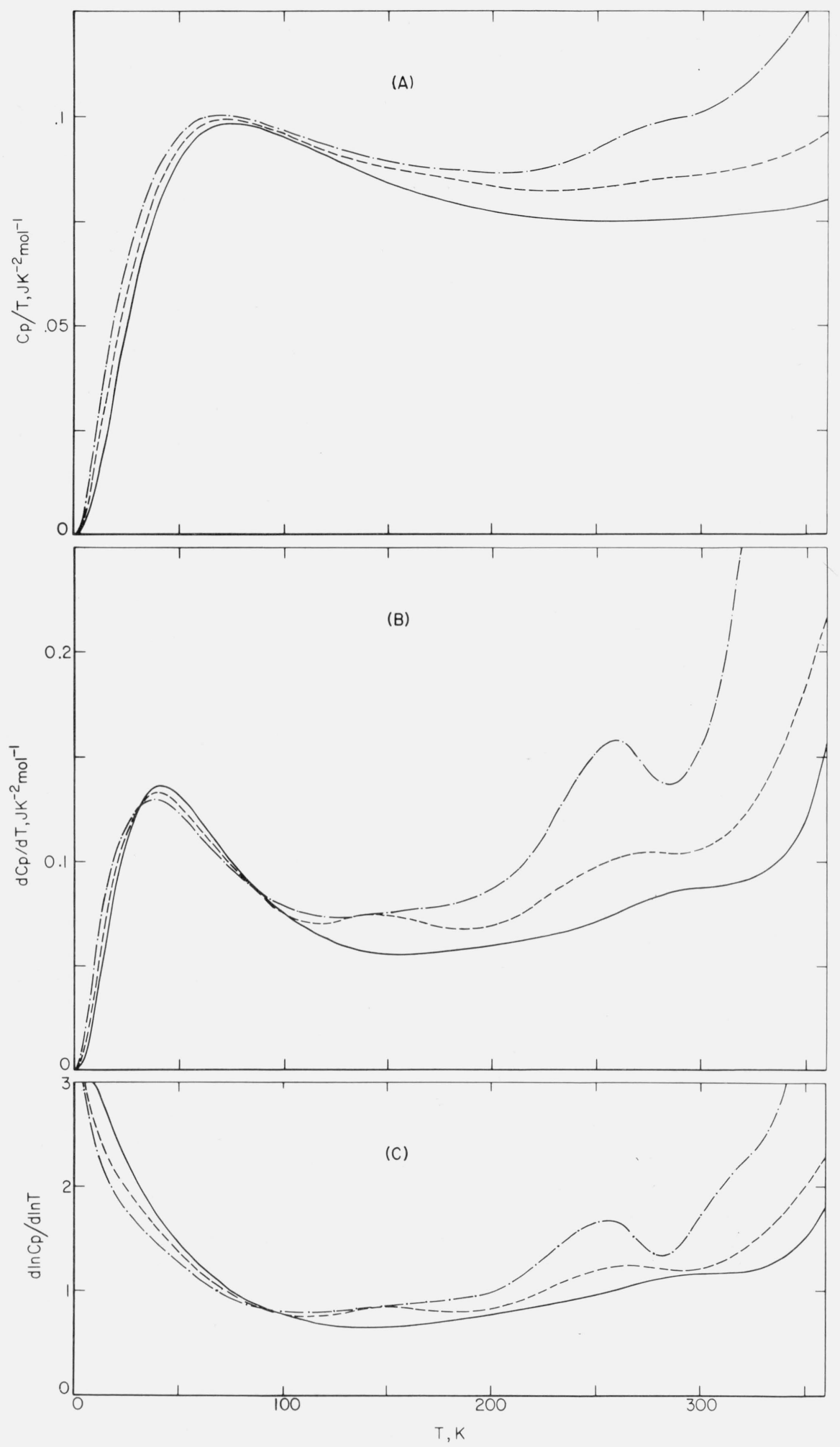

Figure 3. (A) $C_{p} / T$ versus $T$ Plot for Polyethylene.

(B) $d C_{p} / d T$ versus $T$ Plot for Polyethylene.

(C) $d \ln C_{p} / d T$ versus $T$ Plot for Polyethylene.

estimated crystalline, $-\longrightarrow$ linear (SRM 1475 as received), $\longrightarrow$ branched (SRM 1476 as received) 


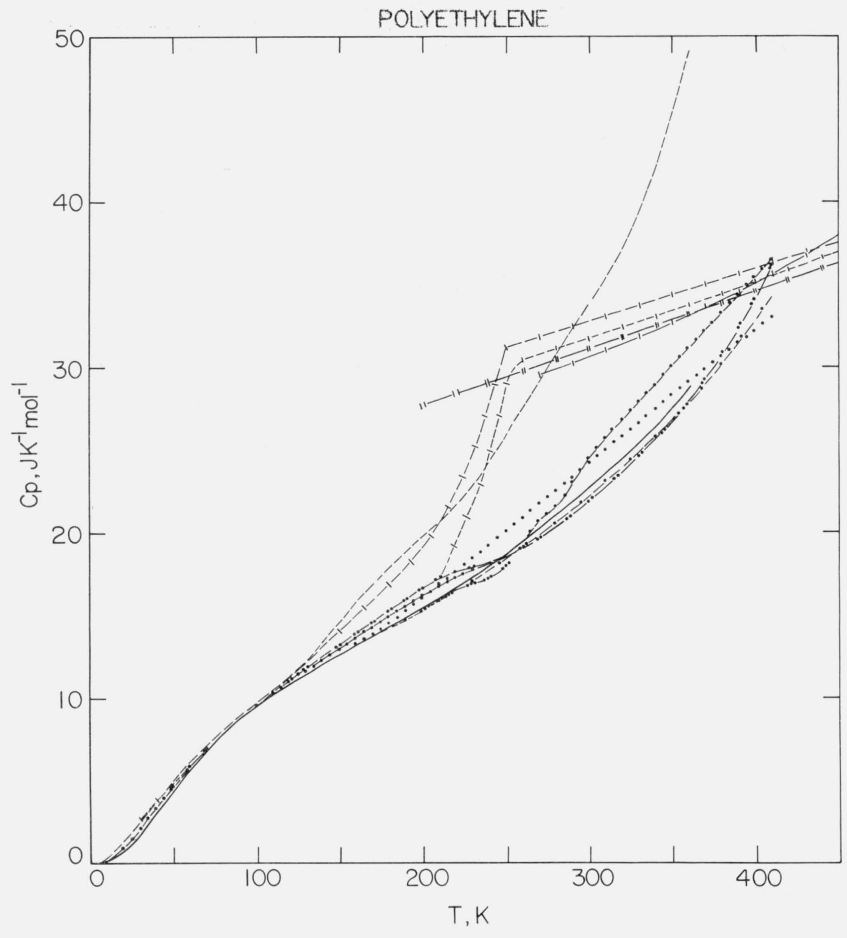

FIGURE 4. Estimated heat capacity of crystalline and amorphous linear polyethylene.
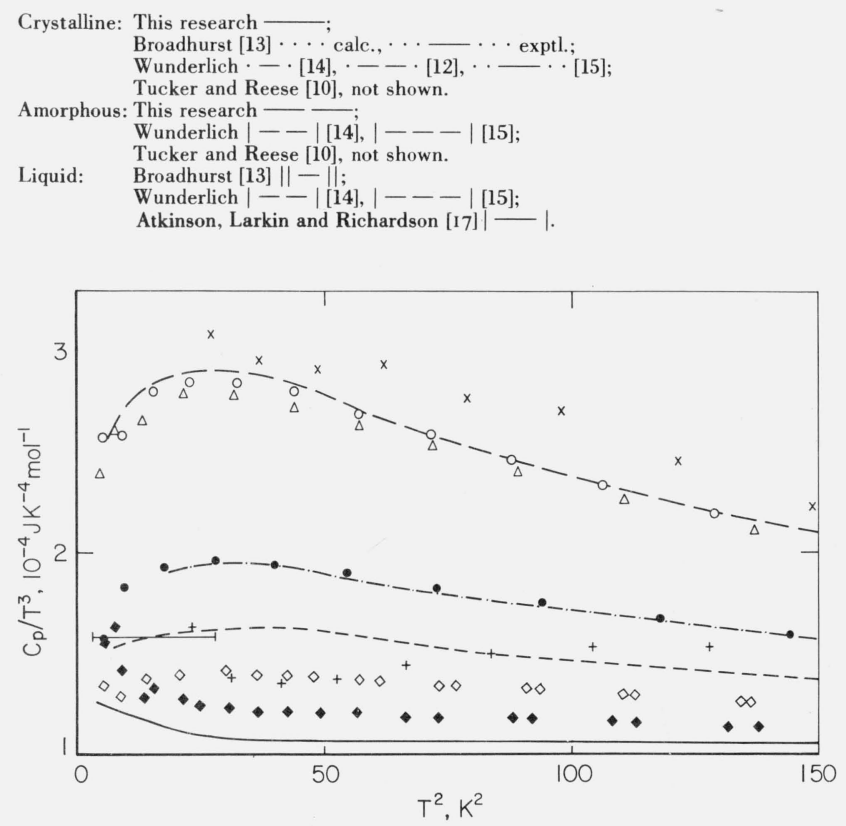

FIGURE 5. Low temperature heat capacity of polyethylene.

This work, Linear (SRM 1475): as received [I], $>$ slow-melt crystallized, pressure crystallized, - estimated 100 percent crystalline; Branched (SRM 1476) [1]: 0 as received. $\triangle$ annealed. Isaacs et al. [8]: $-\models$. Tucker et al. [10]: $-\frac{14}{+}$ branched. received. $\triangle$ annealed. Isaacs et al. [8]: - Westrum [11]: $\times$ branched (DYNH), + linear (Marlex 50).

is probably due to their respective similarities in densities. The difference in the densities for the linear polyethylene samples is about $0.004 \mathrm{~g} \mathrm{~cm}^{-1}$ and that for the branched samples is about $0.01 \mathrm{~g} \mathrm{~cm}^{-1}$.
The linear extrapolation of $C_{p}$ versus crystallinity below $5 \mathrm{~K}$ is probably strongly influenced by the $C_{p}$ of the pressure-crystallized sample, which shows an upsweep in $C_{p} / T^{3}$ as the temperature is lowered. The reason for this particular behavior to show up only in the sample consisting of mainly extended chain crystals is unknown. If the data of the pressure-crystallized sample below $5 \mathrm{~K}$ is not used in the extrapolation, $C_{p} / T^{3}$ for the crystalline phase below $15 \mathrm{~K}$ is within 5 percent of a constant $1.05 \times 10^{-4} \mathrm{~J} \mathrm{~K}^{-4} \mathrm{~mol}^{-1}$. Tucker and Reese [10] obtained a value of $1.104 \times 10^{-4}$ $\mathrm{J} \mathrm{K}^{-4} \mathrm{~mol}^{-1}$ for $C_{p} / T^{3}$ at $0 \mathrm{~K}$.

A sensitive way of detecting any irregularities in the heat capacity behavior of an individual sample is to remove from the observed heat capacity the contribution from the relatively smooth crystalline heat capacity. The differences in the heat capacity of the three linear polyethylene samples, derived from SRM 1475, from the extrapolated crystalline heat capacity are plotted in figure 6 . The short vertical bars at various temperatures indicate the magnitude of 1 percent of extrapolated heat capacity for crystalline linear polyethylene. For the two high density samples, systematic deviations due to the quenching and annealing processes are noticable in the temperature region from 170 to $240 \mathrm{~K}$. The heat capacity of the annealed sample is about 0.1 to 0.2 percent lower than that of the quenched sample. The linear polyethylene sample SRM 1475 in the condition as received [1] has not been subjected to similar annealing and quenching treatments. A hump around $25 \mathrm{~K}$ is observed in the heat capacity differences of all three samples. The occurrence and the magnitude of the humps can generally be attributed to the differences in the specific volumes among the different samples [24]. The heat capacity differences of all three samples reach a minimum around $100 \mathrm{~K}$. As shown in figure 2 , most of the heat capacity values at $100 \mathrm{~K}$ of various linear and branched samples from different laboratories are within a spread of 1 percent.

The heat capacity differences rise sharply after the minimum at $100 \mathrm{~K}$, and level off somewhat around $160 \mathrm{~K}$. This behavior has also been observed by Beatty and Karasz [25] in a sample of high molecular weight linear polyethylene in the temperature region around 130 to $160 \mathrm{~K}$ and was considered by them to be the glass transition region for polyethylene. However, the heat capacity differences in figure 6 indicate another region of rapid rise around 230 to $270 \mathrm{~K}$. In this temperature range, Beatty and Karasz have only noted a change of slope in the heat capacity behavior of their sample. Because the changes involved in the heat capacity "irregularities" are in the order of a few percent and spread over a wide temperature range, heat capacity determination alone may not be sufficient to indicate the occurrence of the glass transition in semicrystalline polyethylene.

Heat capacities of linear polyethylene from various literature sources are compared in figure 7 with the extrapolated heat capacity for crystalline linear polyethylene as the base line. The comparisons of branched polyethylene data, including the study of SRM 1476 


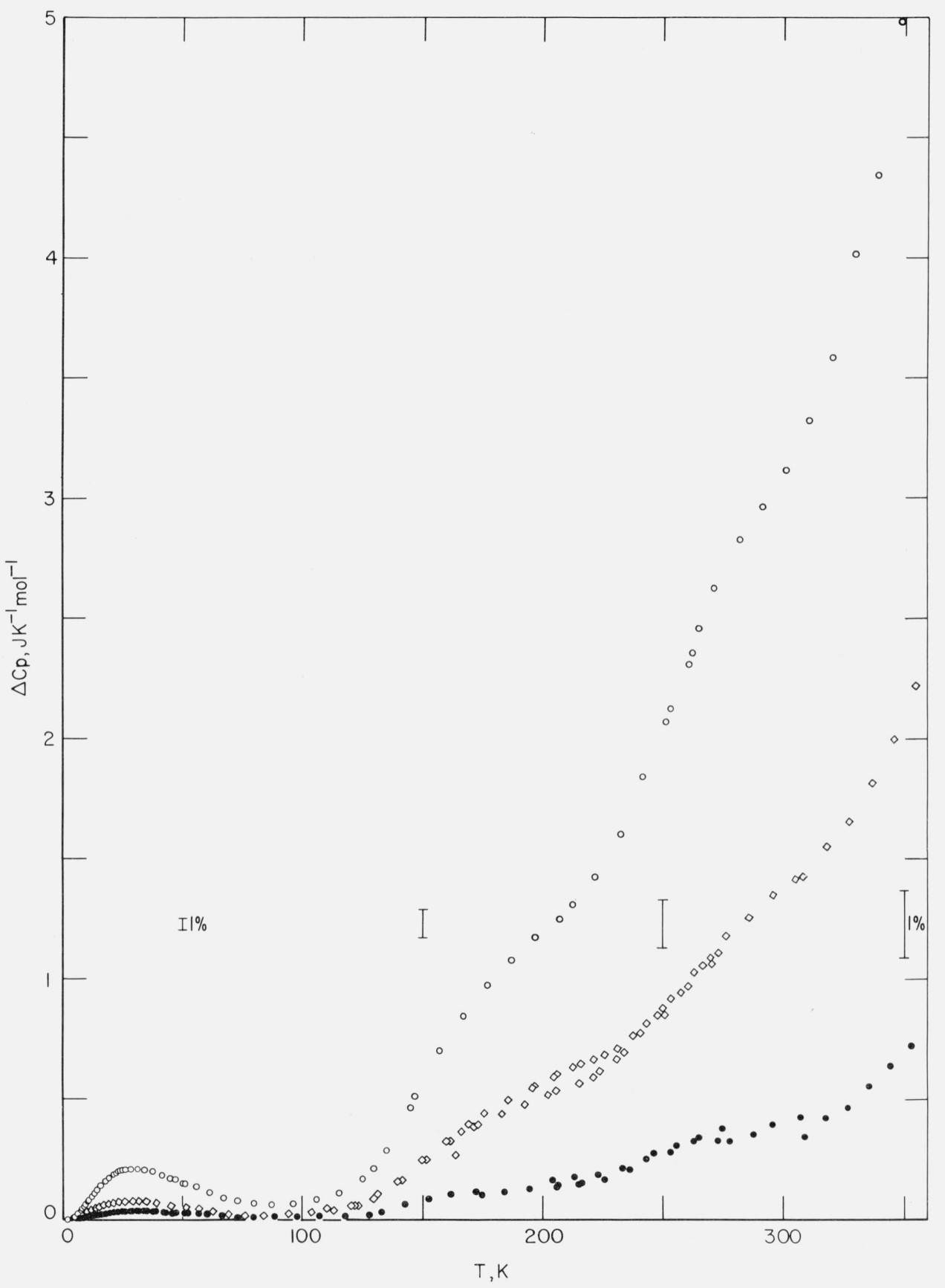

FIGURE 6. Comparison of heat capacities of linear polyethylene samples versus estimated crystalline heat capacity.

SRM 1475: $\bigcirc$ as received [1]. $\nabla_{\text {slow }}$ crystallized,

from this laboratory [1] are shown in figure 8 . The data are included in the comparison only if they are reported in tabular or analytical form. Data reported in graphical form are not included. When heat capacity values are reported at rounded temperatures, the curves shown in figures 7 and 8 may have been arbitrarily smoothed within the limits of the roundoff error of the reported values.
The results of the comparison shown in figures 7 and 8 are in general self-explanatory. A hump around 25 $\mathrm{K}$ in the difference curves, similar to that shown in figure 6, appears in all low temperature measurements. Two regions of more abrupt rise in heat capacity around 150 and $250 \mathrm{~K}$ may be noticed in the studies of linear polyethylene samples by Dainton et al. [7], and by Westrum [11], similar to the findings from this 

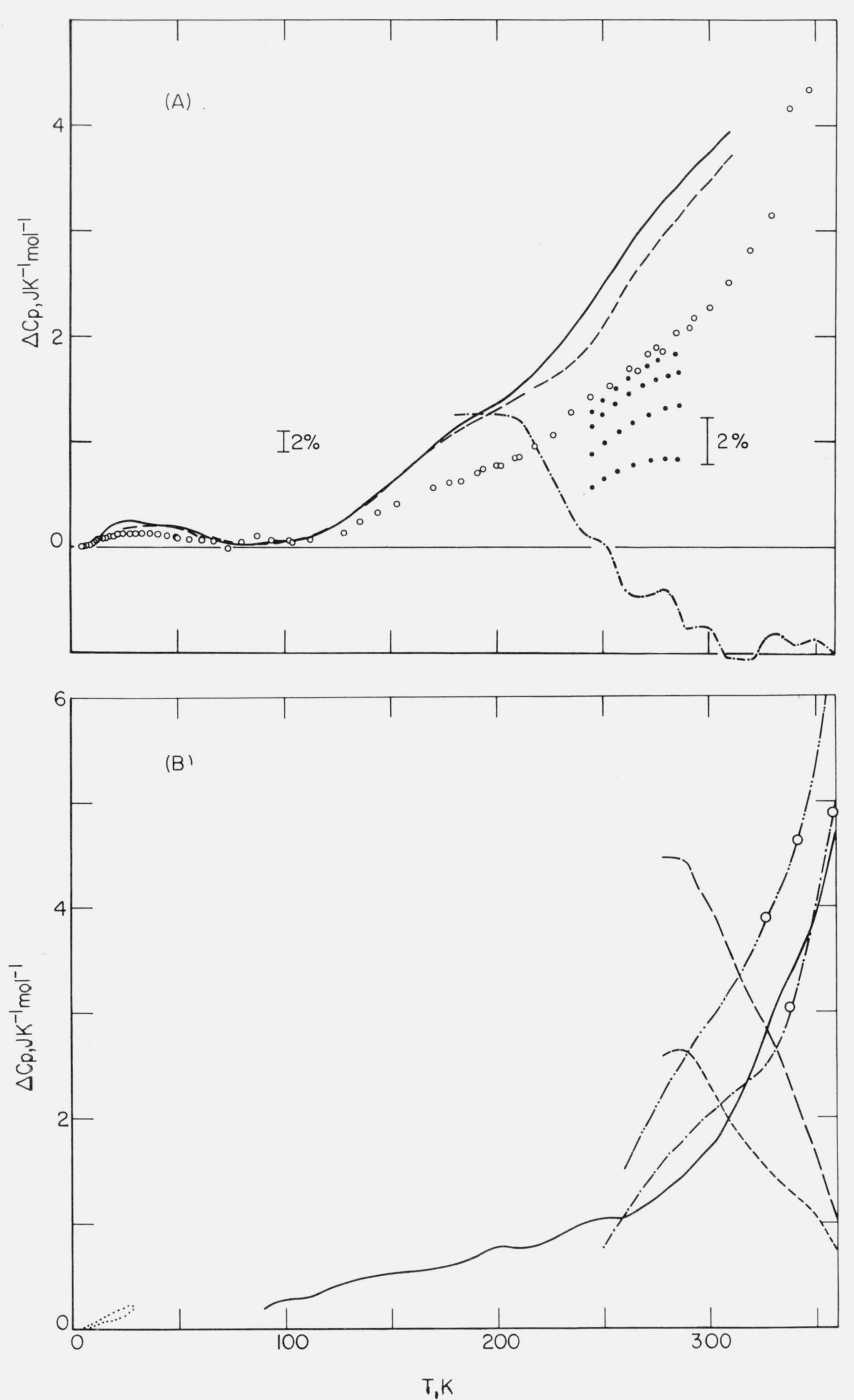

FiguRE 7. Comparison of literature linear polyethylene heat capacity values.

Baseline: crystalline linear polyethylene heat capacity from this work.

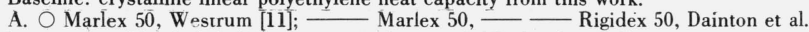
[7]; - - Wurderlich [12]; … single crystals, Richardson [19].

B. Linear, Passaglia et al. [9] … M1 and M2, Tucker et al. [10]; - - Annealed, $-\cdots$ Granular, Dole et al. [13]; - - GD, $---\mathrm{GC}$, Wilski [14].

laboratory [1]. Similar behaviors are noticeable in the measurements on branched samples by Westrum and by this laboratory. The dip around $300 \mathrm{~K}$ in Westrum's heat capacity curve for branched polyethylene is probably effected by long storage of the sample near room temperature. Similar features have been noticed in the branched polyethylene sample studied in this laboratory. The irregularities in Westrum's data around 80 to $90 \mathrm{~K}$ is presumably due to the temperature scales used. The effect of joining the International Practical Temperature Scale of 1948 and the NBS 1955 Provisional Temperature Scale at $90 \mathrm{~K}$ have been noted elsewhere [26, 27].

Sochava's sample $[22,23]$ is probably a branched polyethylene since its heat capacity behavior follows

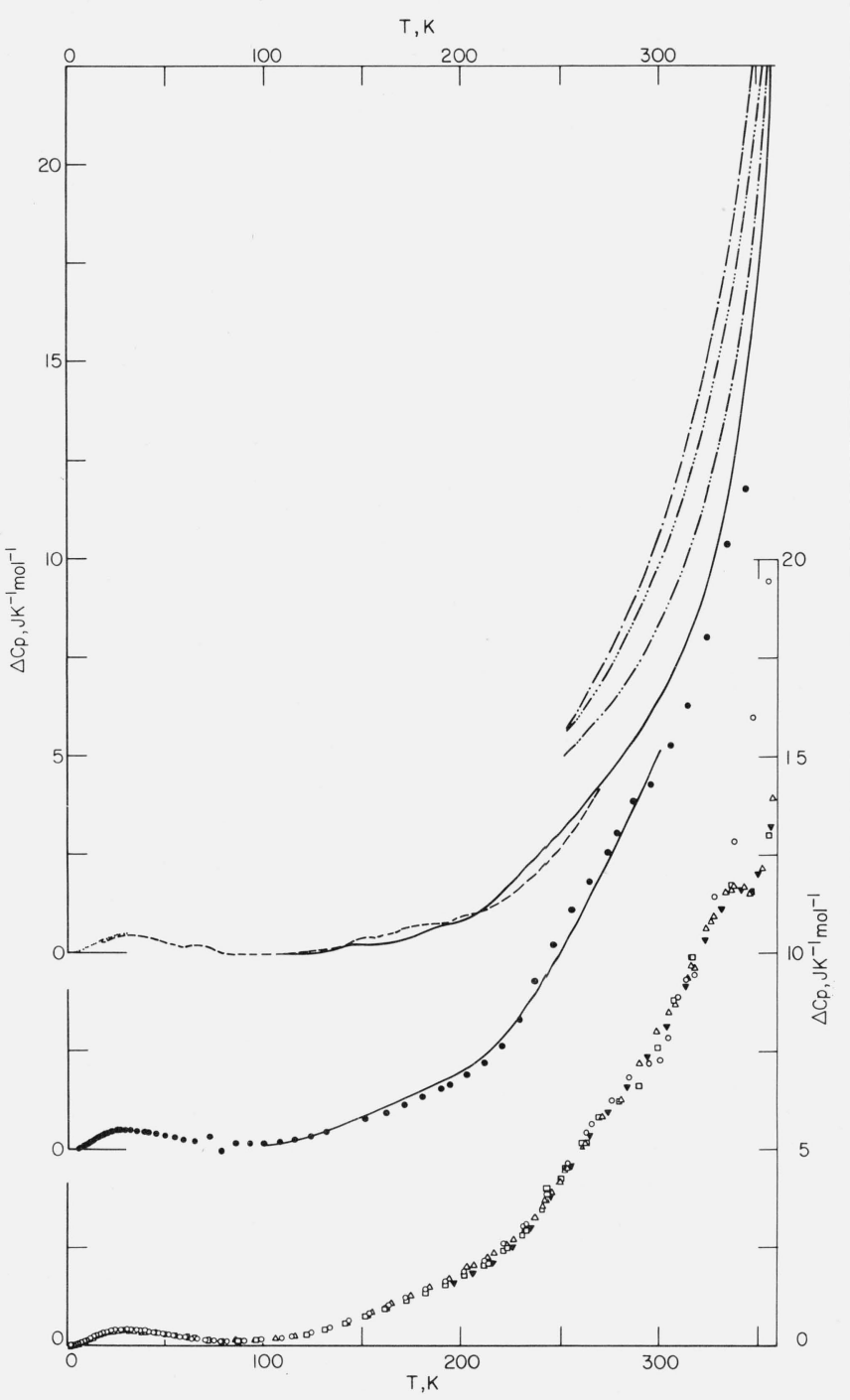

FIGURE 8. Comparison of branched polyethylene heat capacity values.

Baseline: crystalline linear polyethylene from this work.

Lower curves: SRM $1476[\mathrm{I}]$. same legend as in figure 1

Middle curves: E. F. Westrum [11]; — Dainton [7]

Upper curves: $\cdots$ Tucker and Reese [10]; - - Sochava [20, 21]; - Passaglia and Kevorkian [9]; $-. \longrightarrow,-\cdots-$ Dole [19].

the pattern of other branched polyethylene samples. The low temperature behavior of this sample is similar to the branched polyethylene studied by Tucker and Reese [10], Westrum [11] and this laboratory [1]. The high temperature behavior of this sample is very similar to that of the branched polyethylene studied by Passaglia and Kevorkian [9]. Passaglia and Kevorkian's result on linear and branched polyethylene indicates that the heat capacity of the higher density linear sample is about 3-4 percent higher than that of the lower density branched sample at temperatures below $180 \mathrm{~K}$. This indication is probably not real. The authors have pointed out in the paper that there have been experimental difficulties, and they have cited an uncertainty of 3-4 percent in the branched polyethylene and about 1 percent in the linear polyethylene measurements. 


\subsection{Adiabatic Temperature Drift and Glass Transition Temperature}

The glass transition temperature of polyethylene has been assigned a value ranging from 130 to $250 \mathrm{~K}$ depending on the method of observation and on the investigators. The classical calorimetric and dilatometric methods of observing a break in the enthalpy or volume versus temperature curves, or a discontinuity in the heat capacity or thermal expansion coefficient behaviors, have difficulties in clearly demonstrating the occurrence of the glass transition phenomena in highly crystalline polyethylene. In the more sensitive $\Delta C_{p}$ versus $T$ plot, figure 6 , one observes two areas where irregularities occur over a relatively wide temperature range. In both regions the magnitude of the irregularity seems to be proportional to the amorphous content. However, only in the high temperature region, spontaneous thermal relaxation behavior, similar to the behavior of other completely amorphous substances, has been observed for the polyethylene samples. Thus the glass transition of polyethylene is limited to the higher temperature region of the heat capacity irregularities.

The detection of the kinetic nature of the glass transition phenomena in polyethylene by means of the observations of spontaneous adiabatic temperature drift in the glass transition region has been discussed in more detail elsewhere [28]. The following serves as a summary as well as a supplement.

The drift observation is enhanced by quenching and annealing treatments of the sample. In adiabatic calorimetry, the average heating rate during the heat capacity measurement is relatively constant, in the order of $10 \mathrm{~K} \mathrm{~h}^{-1}$. Quenching is defined as a cooling rate to produce a glass at a much greater rate than the normal rate of observation. The cooling rates for quenching the sample in the calorimeter is generally in the order of $5 \mathrm{~K} \mathrm{~min}^{-1}$. The annealing of a glass can either be achieved by a very slow rate of cooling in comparison to the rate of observation, or by holding for a couple of days at temperatures somewhat below the glass transition temperature of the quenched glass. A slow cooling rate of less than $1 \mathrm{~K} \mathrm{~h}^{-1}$ can easily be achieved. When a quenched glass is heated to temperatures near the glass transition region, sufficient mobility in the quenched glass allows it to relax toward the configurations of the supercooled liquid. If the sample is kept in an adiabatic environment, this relaxation shows up as a spontaneous temperature rise of the sample. This phenomena can usually be detected from some $50 \mathrm{~K}$ below the glass transition temperature, for materials having $T_{g}$ around 200 to $300 \mathrm{~K}$. Annealed glass can easily be overheated to temperatures above its glass transition temperature before its viscosity decreases to a low enough level to allow significant configurational relaxation to occur. Therefore the over-heated annealed glass relaxes toward the supercooled liquid state by spontaneously lowering its temperature under adiabatic conditions. The spontaneous heating and cooling of the quenched and annealed vitreous sample near the glass transition region have been observed for many vitreous materials as cited in reference [28]. Drifts have also been noted in some recent calorimetric studies on vitreous substances [29, 30]. The drift method has also been applied to the locating of the $T_{g}$ of partially crystalline poly-1-pentene [31].

The total observed temperature in adiabatic calorimetry may come from three different sources, namely, the thermometer current, the heat transferred between the calorimeter and the shield, and the thermal effects generated by the sample itself. A steady thermometer current of $2 \mathrm{~mA}$ flowing through a $25-\Omega\left(0{ }^{\circ} \mathrm{C}\right)$ platinum resistance thermometer produces approximately $0.1 \mathrm{~T} / 273 \mathrm{~mW}$ of power. At around $250 \mathrm{~K}$, under strict adiabatic conditions this power dissipation will cause a positive drift of the order of $0.03 \mathrm{mK} \mathrm{min}$ m $^{-1}$ to appear for the calorimeter loaded with polyethylene. The heat transfer coefficient for the loaded calorimeter at $250 \mathrm{~K}$ is about $1 \mathrm{mK}$ min $^{-1}$ per kelvin of temperature difference between the calorimeter and the adiabatic shield. With the short term temperature difference settable and controllable to within $1 \mathrm{mK}$, the positive drift produced by the thermometer current can be detected. Long term systematic variation in the drift has been observed to occur in the order of $0.05 \mathrm{mK} \mathrm{min}^{-1}$ per hour. The drift observable at the same temperature on different days may be different due to the residual emf in the differential thermocouple circuit. The residual emf in the heater and in the thermometer circuits is always less than $1 \mu \mathrm{V}$ and varies slowly in time and temperature. Assuming a similar order of magnitude of the residual emf in the differential thermocouple circuit, a temperature difference in the order of $20 \mathrm{mK}$ may exist between the adiabatic shield and the sample container. Coupled with the thermal transfer coefficient, a long term variation in the drift in the order of $0.05 \mathrm{mK} \min ^{-1}$ may be expected.

In the temperature region around $150 \mathrm{~K}$, some irregularity shows up in the $\Delta C_{p}$ plot, figure 6 . The magnitude of the irregularity seems to be more pronounced in the linear sample than that in the branched sample, figure 8 , it also seems to be proportional to the amorphous content. However no significant and long thermal drift is observed in this temperature region. One might associate this irregularity to the onset of the so-called crankshaft motion or other forms of segmental motion of the polyethylene chain in the amorphous phase. Branching of the chain increases the volume to be swept by this kind of motion and thus may hinder or move the onset to much higher temperature. A more pronounced $C_{p}$ irregularity has been observed in a high molecular weight linear poly. ethylene sample [25].

Near $250 \mathrm{~K}$, heat capacity irregularities show up in all three linear polyethylene samples, figure 6 . The magnitude of the irregularity seems to be proportional to the amorphous content of the sample. Similar behavior may be seen in branched samples, figure 8 . Significant spontaneous warming and cooling of the sample after quenching and annealing, respectively, 
also show up in this temperature region. The calorimetric temperature drift, observed at $30 \mathrm{~min}$ after the termination of each energy input for the three linear polyethylene samples under both quenched and annealed conditions, are shown in figure 9. The drift

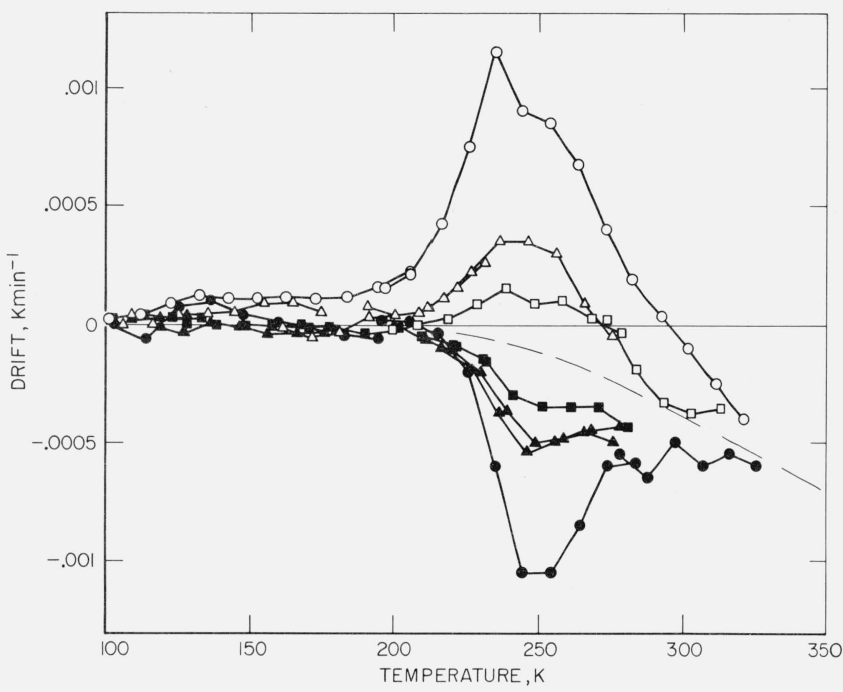

FIGURE 9. Spontaneous adiabatic temperature drift of linear polyethylene.

SRM 1475 as received, $\triangle \mathbf{A}$ slow melt-crystallized, $\square$ pressure crystallized. Open symbols, quenched samples; filled symbols, annealed samples. Dashed line represents drift due to heat exchange alone under similar operational conditions.

behavior for the branched polyethylene sample was shown in reference [1]. Although the maximum magnitude of the observed drift is about one order of magnitude smaller than that observed in completely vitreous materials, the observed magnitude is still one order of magnitude greater than the contribution from the thermometer current and from the heat leak in the calorimeteric system. The magnitude of the maximum observed drift seems to be proportional to the amorphous content of the sample. However, the temperature at which the maximum drift occurs does not vary significantly as a function of the crystallinity of the sample. All three quenched samples show spontaneous warming drift peaks at temperatures around $235 \mathrm{~K}$, and the annealed samples indicate cooling peaks near $245 \mathrm{~K}$. Therefore in analogy with the behaviors observed for completely vitreous materials as cited in reference [28] and elsewhere, the glass transition temperature for the linear polyethylene sample may be assigned a value of $240 \pm 5 \mathrm{~K}$. This assignment is in good accord with a recent volume relaxation study on polyethylene samples [32]. The drifts for the two densified samples have been observed along with the heat capacity measurements reported in this paper. During the heat capacity measurements for the SRM 1475 in the condition as received [1], no annealing and quenching treatments were applied. Therefore the same sample was reloaded in the calorimeter and the drift behavior was observed following similar annealing and quenching treatments to those for the two high density samples.

The author wishes to thank C. H. Pearson in assisting in the calorimetric measurements and D. W. Brown for the preparation of the pressure-crystallized sample. He also wishes to thank G. T. Davis, Cheng-Hsiung Hsieh, ${ }^{3}$ R. G. Christensen and G. Ross for the characterization of the samples by small-angle X-ray diffraction, IR spectroscopy, viscosity and gel-permeation chromatography, respectively.

\section{References}

[1] Chang, S. S., and Bestul, A. B., J. Res. Nat. Bur. Stand. (U.S.), 77A (Phys. and Chem.), No. 4, 395-405 (July-Aug. 1973).

[2] Sterrett, K. F., Blackburn, D. H., Bestul, A. B., Chang, S. S., and Horman, J. A., J. Res. Nat. Bur. Stand. (U.S.), 69C (Eng. and Instr.), No. 1, 19-26 (Jan.-Mar. 1965).

[3] Wunderlich, B., and Arakawa, T., J. Polymer Sci. A-2, 3697 (1964).

[4] Ross, G., and Frolen, L., J. Res. Nat. Bur. Stand. (U.S.), 76A (Phys. and Chem.), No. 2, 163-170 (Mar.-Apr. 1972).

[5] Kardos, J. L., Baer, E., Geil, P. H., and Koenig, J. L., Kolloid Z. 204, 1 (1965).

[6] Calvert, P. D., and Uhlmann, D. R., J. Polymer Sci. A-2, 10, 1811 (1972).

[7] Dainton, F. S., Evans, D. M., Hoare, F. E., and Melia, T. P., Polymer 3, 277 (1962).

[8] Isaacs, L. L., and Garland, C. W., J. Phys. Chem. Solids 23, 311 (1962).

[9] Passaglia, E., and Kevorkian, H. K., J. Appl. Polymer Sci. 7, 119 (1963).

[10] Tucker, J. E., and Reese, W., J. Chem. Phys. 46, 1388 (1967).

[11] Westrum, E. F., Jr., unpublished.

[12] Wunderlich, B., J. Phys. Chem. 69, 2078 (1965).

[13] Broadhurst, M. G., J. Res., Nat. Bur. Stand. (U.S.), 67A (Phys. and Chem.), No. 3, 233-240 (May-June 1963).

[14] Wunderlich, B., J. Chem. Phys. 37, 1203 (1962).

[15] Wunderlich, B., and Baur, H., Adv. Polymer Sci. 7, 261 (1970).

[16] Wunderlich, B., J. Chem. Phys. 37, 1207 (1962).

[17] Atkinson, C. M. L., Larkin, J. A., Richardson, Y. M. J., J. Chem. Therm. 1, 435 (1969).

[18] Wunderlich, B., and Dole, M., J. Polymer Sci. 24, 201 (1957).

[19] Richardson, M. J., Trans. Faraday Soc. 61, 1876 (1965).

[20] Wilski, H., Kunstoffe 50, 281 (1960).

[21] Dole, M., Hettinger, W. P., Jr., Larson, N. R., and Wethington, J. A., Jr., J. Chem. Phys. 20,781 (1952).

[22] Sochava, I. V., Doklady Akad. Nauk SSSR 130, 126 (1960).

[23] Sochava, I. V., and Trapeznikova, O. N., Soviet Phys. Doklady 2, 164 (1957).

[24] Guttman, C. M., J. Chem. Phys. 56, 627 (1972).

[25] Beatty, C. L., and Karasz, F. E., Bull. Am. Phys. Soc. Ser. II, 16, 1391 (1971).

[26] Furukawa, G. T., and Reilly, M., J. Res. Nat. Bur. Stand. (U.S.), 69A (Phys. and Chem.), No. 1, 5-12 (Jan.-Feb. 1965).

[27] Roder, H. M., J. Res. Nat. Bur. Stand. (U.S.), 69A (Phys. and Chem.), No. 6, 527-530 (Nov.-Dec. 1965).

[28] Chang, S. S., J. Polymer Sci. Part C, 43, (1973).

[29] Matsuo, T., Oguni, M., Suga, H., and Seki, S., Proc. Japan Acad. 48, 237 (1972).

[30] Haida, O., Matsuo, T., Suga, H., and Seki, S., Proc. Japan Acad. 48, 489 (1972).

[31] Bourdariat, J., Isnard, R., and Odin, J., IUPAC Intl. Sym. Macromol., Aberdeen, September 1973.

[32] Davis, G. T., and Eby, R. K., J. Appl. Phys. 44, 4274 (1973).

(Paper 78A3-819)

${ }^{3}$ Guest Worker at NBS from the Union Industrial Research Institute, Hsing-Chu, Taiwan, Republic of China. 